\title{
A Propósito dos Comentários Feitos ao Artigo A Estruturação de Dissertações e Teses em Administração: Caracterização Teórica e Sugestões Práticas
}

\author{
Pedro Lincoln Mattos
}

Inicio com menção elogiosa à idéia da RAC de propor debate explícito em suas páginas, nominados os participantes, como forma de atividade científico-acadêmica. Note-se o que há de diferente nisso: o meu interlocutor fica claro - e agora falo como autor desta tréplica - pois dirijo-me ao grande auditório da academia, mas refiro-me proximamente ao contexto de discussão levantado por duas pessoas, pesquisadoras que conheço, respeito e estimo. Isso modera agora meu discurso, torna-o mais cuidadoso e, acima de tudo, o obriga situar-se de outro ponto de vista, o outro lado de tudo o que se afirma.

As réplicas me fizeram refletir e, em minha percepção subjetiva do que intencionavam suas autoras, avançar na minha própria compreensão do assunto. Limito-me a duas questões. Primeira: que há, afinal, proposto no artigo, que já não se contenha na prática atual de estruturação de teses e dissertações entre nós? Segunda: não deveria haver, no proposto pelo artigo, diferença clara entre dissertações de mestrado e teses de doutorado?

\section{Da Forma ao 'Espírito' das Práticas}

Referindo-se ao artigo, diz Sylvia Vergara: “ao fazer a crítica às formas pelas quais teses, dissertações e artigos acadêmicos são produzidos, o autor assevera que estão presos a um formalismo pouco contributivo à 'verdadeira construção do conhecimento'. Eis aí seu desconforto e motivação para o texto”. E prossegue ela: "formula outra proposta, ainda formal: que teses, dissertações e artigos acadêmicos sejam estruturados em três partes. São elas: (1) o estado da questão; (2) a argumentação; (3) a conclusão. Ou, como nos velhos tempos, (1) introdução; (2) desenvolvimento; (3) conclusão”. E, enfim, mais adiante: "se, claramente, há de se concordar que os aspectos formais não devem sobrepujar-se ao conteúdo do que se apresenta, fica difícil, no entanto, admitir que a academia sugira a seus membros, iniciantes ou não, que a prática metodológica seja 'sobretudo uma prática de regras metodológicas’. Até onde me é dado perceber, 
o movimento da academia é no sentido de oferecer sugestões práticas, como o faz Pedro Lincoln, conforme explicitado no título do seu trabalho. Essas sugestões da academia são plurais, isto é, ela não elegeu um único tipo de estruturação - universal, portanto - para que trabalhos científicos sejam apresentados. Ao aceitar propostas variadas, no entanto, o que a academia não faz é deixar de reconhecer a necessidade de que estejam presentes alguns elementos. Todos eles também aparecem na proposta do autor: problematização de fatos e idéias, objetivo, hipótese, justificativa/relevância (finalidade social, 'ato perlocucionário de fala'), argumentação própria ou de outros autores e conclusões”.

Com argúcia, a professora e cara amiga foi ao ponto, dando-me agora oportunidade para esclarecer certas coisas e reafirmar outras. Quando, ainda no segundo parágrafo do artigo, eu disse que o formalismo desenvolve "o mundo metodológico da forma em prejuízo da discussão do critério" e que "o formalismo é essa hipertrofia do valor forma", deveria ter antes me explicado com essa estranha expressão: “o formalismo é um espírito". Um espírito presente à comunicação. Não é fazer isso ou aquilo em um texto, é soprar nele todo: "o importante aqui é fazer assim”. É um hábito de usar a linguagem de certa maneira, produzindo um significado perlocucionário como este que se acaba de referir. Embora não explícito na letra, ele é muito bem entendido pelo interlocutor, principalmente o que se inicia no diálogo acadêmico. Porque o uso de toda forma cria consigo um contexto de significação mais amplo, e a estrutura está entre os dois como algo tanto dinâmico quanto formal, porque consiste no uso da forma. No artigo, não rejeito a forma, mas quis criticar certo uso da forma e sugerir - com base em teoria bem aceita - outro, o da retórica argumentativa, que, por criar o contexto de presença de um auditório crítico, cujo acordo se deseja obter, é menos vulnerável ao formalismo. Só isso.

Insisto em que a diferença entre essa e a estruturação como relatório de pesquisa, trabalho escolar solitário ou demonstração de habilidade redacional acadêmica, deve ser entendida além da forma, mas já está sutilmente nela. Vejamse alguns exemplos tirados do próprio contexto aqui tratado.

Ao dizer: "não há conteúdo sem forma” ou "não há significado sem sua forma de expressão", que diferença isso faz, se sabemos que o conteúdo da forma é o seu sentido? Mas faz, sim. Na primeira expressão penso em uma fôrma que encerra uma matéria qualquer diferente dela; na segunda, destaco um significado possuidor de forma e me reporto ao contexto de expressão humana.

Ao sugerir a estruturação de teses e dissertações em (1) estado da questão, (2) argumentação e (3) sua conclusão, significa, mesmo esquematicamente, coisa diferente de (1) introdução, (2) desenvolvimento e (3) conclusão. A primeira formulação me põe necessariamente em certo contexto de comunicação, ao pas- 
so que a segunda pode indicar também outros como o de um trabalho escolar, e não sugere interlocutores.

Ao falar do aspecto formal da estrutura listando "elementos que a academia não pode deixar de reconhecer nas dissertações e teses: problematização de fatos e idéias, objetivo, hipótese, justificativa/relevância, argumentação própria e de outros etc.”, crio matiz diferente daquela descrição articulada da estrutura formal que usei no texto do artigo, quando disse (penúltima página): "no estado da questão [em negrito, porém minúsculas, pois não estou instituindo uma parte formal para as dissertações e teses], o acordo com o auditório exigirá que o texto anuncie, de início, e justifique aquilo para que se faz ou a que se propõe o discurso: sua motivação e seu objetivo etc.”; quando disse “a argumentação, centro do discurso retórico, exigirá” isso e aquilo - e remeto agora o leitor ao meu texto original - certamente fiz referência a algo muito flexível e dinâmico, mesmo que eventualmente tenha sido reinterpretado como, afinal, fazendo o mesmo que listar elementos que devem constar de dissertações e teses.

Esses usos diferentes da linguagem são apenas exemplos, mas dizem muito. $\mathrm{O}$ objeto de insistência aqui é a diferença de abordagem à questão da estrutura. É tênue o limite no qual o formal - sem dúvida importantíssimo - permanece sob foco e passa ao centro do palco. Por outro lado, são permanentes a atenção e a luta para que a forma não se enrijeça e bloqueie a natural profundidade dos significados da expressão humana, porque quanto mais se generalizam, mais tendem as práticas - no caso as de trabalhos acadêmicos - a viver apenas do significado de face. E, na minha opinião, aquela atenção e aquela luta estão sendo perdidas entre nós, na academia.

A propósito - e sem referir-me agora aos comentários de Sylvia - não concordo com certa opinião corrente de que "no fim, tudo dá no mesmo, e se reduz à prática”. A dificuldade das pessoas é justamente perceber o espírito diferente de práticas semelhantes. E ele pode fazer-se marcar pela insistência em diferenciar, até mesmo por expressões diferentes (no caso, auditório, racionalidade argumentativa, lugares de acordo, convencimento e não persuasão etc.), um contexto de significação diferente.

Enfim, preciso esclarecer que afirmando ser o desvio, que chamo de formalismo, pouco contributivo “à verdadeira construção do conhecimento” refiro-me à relevância histórica e social de nosso trabalho acadêmico. Ele precisa, em espaço próprio, fazer avançar de forma crítica a compreensão que a sociedade tem dos problemas e situações de que vive. Fora disso, caminhamos para a desimportância social. Deixar-nos-ão falando uns para os outros na linguagem estereotipada que desenvolvemos. Vejo o formalismo no meio disso. 


\section{À Procura da Especificidade das Dissertações VIS-À-VIs as TESES}

Afinal, ao falar de estrutura, há diferença substantiva entre dissertações e teses? Será tudo apenas uma questão de grau de exigência? Estas são perguntas cuidadosamente evitadas em nossa prática diária... A questão da especificidade das dissertações de mestrado em face do que constituem as teses de doutorado, não foi levantada per se por Moema Siqueira, é verdade, mas pressuposta ou indiretamente referida por ela quando considerou um pouco utópica a estruturação de dissertações como arte argumentativa. Não pretendo, por isso, também propriamente respondê-la, até mesmo por óbvias restrições de espaço, mas apenas identificá-la e desdobrar brevemente algo que sobre ela se afirma dentro do artigo.

Este praticamente não diferencia, para efeito de estruturação, dissertações e teses. Moema vê nisso um problema, e pode estar certa.

Lembremos, de início, que, há uns cinco anos, o próprio sentido dos mestrados acadêmicos foi entre nós posto em discussão, com o surgimento dos mestrados profissionais (CAPES, 1995 e 1998), argumentando-se que, de fato, a formação do pesquisador-professor é visada e supostamente obtida com o doutorado. $\mathrm{O}$ mestrado acadêmico teria tido sua função histórica de transição, quando o sistema de pós-graduação em Administração no Brasil estava em formação, ali se abrigando todas as intenções da demanda reprimida. A discussão não foi aprofundada, talvez pelas razões práticas da inércia, talvez por parecer natural a adequação do nosso a certos modelos internacionais que têm no mestrado acadêmico (o MsC, por exemplo), um degrau ou estágio para o doutorado. Até mesmo supôs-se passagem agilizada daquele a este e concessão compensatória do título de mestre aos que, nesse caso, não conseguissem concluir o doutorado. Fica, de qualquer forma, algo mal resolvido nessa questão, às custas de que representa um ou dois anos a mais no sistema de pós-graduação stricto sensu. De fato, sabe-se que o pesquisador só se forma com muito mais tempo de exercício da pesquisa com seus pares, exercício que, então, não haveria por que retardar com a anteposição do mestrado. Por outro lado, os rumos tomados pela rápida expansão dos mestrados profissionalizantes - muito além, por sinal, da formação de densidade conceitual sobre eles - provocou certo retraimento cauteloso da academia a práticas curriculares, comprovadamente de boa qualidade, como poderiam dizer-se os mestrados acadêmicos.

Isso para apontar a questão da identidade dos mestrados vis-à-vis o doutorado e justificar por que o artigo preferiu omiti-la. 
A única idéia relativa a tal questão, está presente no artigo quando se diz, na perspectiva de Thomas Kuhn sobre a comunidade científica, que "dissertações e teses são rituais de entrada e de maturidade nas comunidades de praticantes da arte”. Quis-se ver assim o mestrado em uma função de iniciação, de entrada, enquanto o doutorado representaria certa maturidade, o grau ordinário de todos os pesquisadores. A ausência de discussão própria sobre o sentido do mestrado (e do doutorado) na formação do pesquisador, de que se falou acima, enfraquece, sem dúvida, essa caracterização mestrado-iniciação, doutorado-maturidade. Tornaa pouco mais que apenas empírica, reconheço.

Contudo, sobre certa inviabilidade de esperar de mestrandos, até mesmo nas circunstâncias de agilização do curso, postas pela CAPES, competência para estruturarem suas dissertações como retórica argumentativa, objeção levantada por Moema Siqueira, tenho dúvidas. Mais difícil é aprender em pouco mais de um ano os sofisticados meandros das estratégias metodológicas de pesquisa, nos quais o modelo atual põe seu foco. A argumentação é um processo comunicativo muito mais próximo da experiência ordinária. A adaptação dos jovens mestrandos poderia ser, ao contrário, mais fácil, mesmo que muitos de seus argumentos não resistissem à crítica de pesquisadores seniores, o que não seria de estranhar. A carga na competência formal não produz, de qualquer forma, saltos de maturidade. Por outro lado, pergunta-se: se o ambiente normal da vida acadêmica é o debate crítico de posições e crenças, por que não iniciar nisso mesmo os jovens entrantes, por meio de uma estrutura de dissertação que destaque a capacidade de argumentação racional sobre proposições, mesmo simples, propostas a públicos mais amplos? 